\title{
Words of Welcome by Prorektor Prof. B. ILSCHNER
}

On behalf of the Rector of the University of Erlangen-Nürnberg I would like to extend a very sincere and cordial welcome to the participants of this conference.

Supposed one would define an „Internationality Coefficient" for conferences, this one in Bamberg would certainly obtain a value quite close to 1 . In fact, it is a particular pleasure to welcome, at this occasion, so many foreign scientists. Internationality is a prominent feature of modern science - this degree increasing with the increasing effort which has to be made in order to solve those problems which could not yet be solved by our fathers and forefathers. This link between effort and international cooperation is particularly pronounced in the socalled "Big Science" - and astronomy belongs (not only since yesterday) most certainly to Big Science.

Astronomy has recently gained much popularity again. More people than ever before are looking up into the star-sprinkled skies - still more like to have a look onto the moon's surface on the TV screen, sitting in their cosy chair. This sort of popular astronomy is certainly far from what you have meant in your conference. Your topic was representative for science which intends to increase our basic knowledge of the world - irrespective of applications. Still: is there not a certain connection between the naive curiosity of Mr. and Mrs. Jones who find it quite interesting to watch Man stepping on the moon - and the sophisticated curiosity of a scientist, who (on quite another level) inquires into the details of variable star behaviour?

I feel that we scientists must be more careful than ever before not to live in a splendid isolation. It is less important that Mr. Jones knows the physical behaviour of stellar systems - but it is very important that he understands to some degree why we do research, why the task of increasing basic knowledge is not an expensive hobby, but is so important for our human community, for giving more sense to our lifes. This "transfer of motivation" is a great responsibility for all of us. Let us hope that the personal talk at an evening like this, with its chance to relax from the stress of the scientific discussion, may also contribute to these broader aspects of our work. 